\title{
Correction to: GC-MS Analysis, Molecular Docking and Pharmocokinetic Properties of Phytocompounds from Solanum torvum Unripe Fruits and Its Effect on Breast Cancer Target Protein
}

\author{
R. Saravanan ${ }^{1} \cdot$ K. Raja ${ }^{1} \cdot$ D. Shanthi ${ }^{1}$ \\ Published online: 10 November 2021 \\ (c) Springer Science+Business Media, LLC, part of Springer Nature 2021
}

\section{Correction to: Applied Biochemistry and Biotechnology https://doi.org/10.1007/s12010-021-03698-3}

The original article has been corrected. The following errors in the Table $1 \& 2$ are listed below.

The original article can be found online at https://doi.org/10.1007/s12010-021-03698-3.

\section{R. Saravanan}

rsaravanan0268@gmail.com

1 Post Graduate and Research Department of Zoology, Dr. Ambedkar Government Arts College, Vyasarpadi, Chennai 600 039, Tamil Nadu, India 


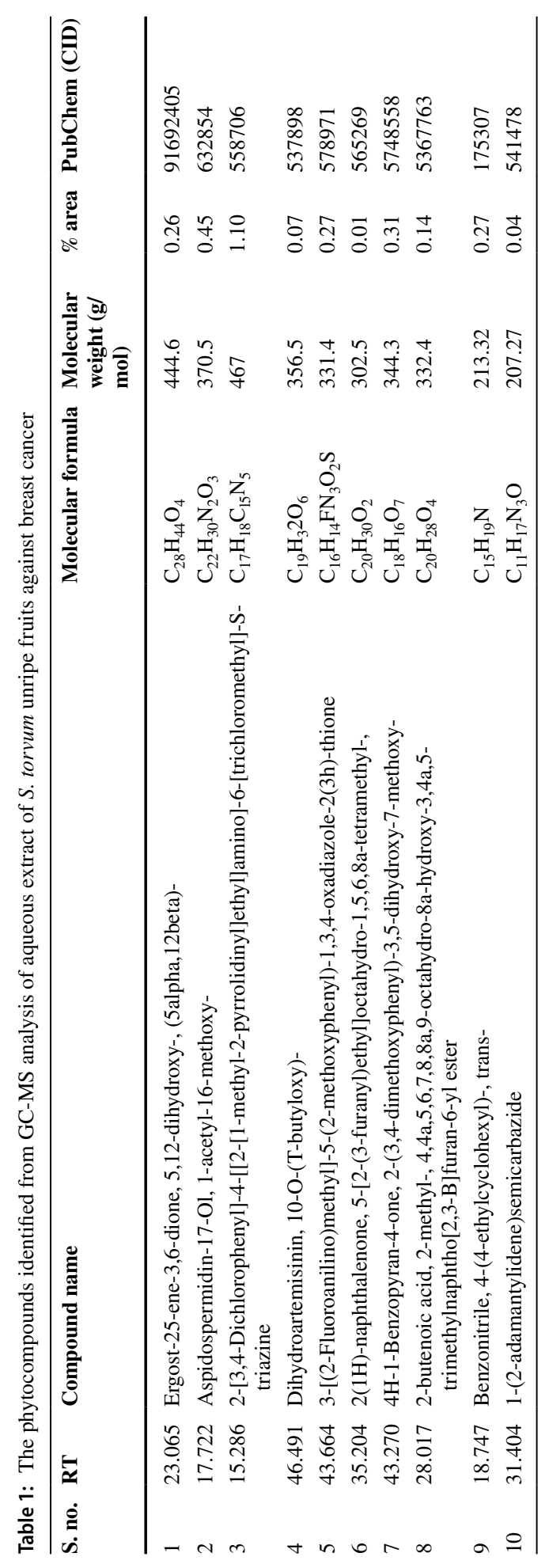


Table 2: The 2D structure of the best identified phytocompounds from GC-MS analysis

\begin{tabular}{|c|c|c|c|}
\hline $\begin{array}{l}\text { S. } \\
\text { No. }\end{array}$ & $\begin{array}{c}\text { PubChem } \\
\text { (CID) }\end{array}$ & Compound Name & 2D Structure of Phytocompounds \\
\hline 1 & \begin{tabular}{|l|l|}
91692405 \\
\end{tabular} & $\begin{array}{l}\text { Ergost-25-Ene-3,6-Dione, 5,12-Dihydroxy-, } \\
\text { (5.Alpha.,12.Beta.)- }\end{array}$ & \\
\hline $2 \mid$ & 632854 & $\begin{array}{l}\text { Aspidospermidin-17-Ol, 1-Acetyl-16- } \\
\text { Methoxy- }\end{array}$ & \\
\hline 3 & 558706 & $\begin{array}{l}\text { 2-[3,4-Dichlorophenyl]-4-[[2-[1-Methyl-2- } \\
\text { Pyrrolidinyl]Ethyl]Amino]-6- } \\
\text { [Trichloromethyl]-S-Triazine }\end{array}$ & \\
\hline 4 & 537898 & Dihydroartemisinin, 10-O-(T-Butyloxy)- & \\
\hline 5 & \begin{tabular}{|l|l|}
578971 \\
\end{tabular} & $\begin{array}{l}\text { 3-[(2-Fluoroanilino)Methyl]-5-(2- } \\
\text { Methoxyphenyl)-1,3,4-Oxadiazole-2(3h)- } \\
\text { Thione }\end{array}$ & \\
\hline
\end{tabular}


Table 2: (continued)

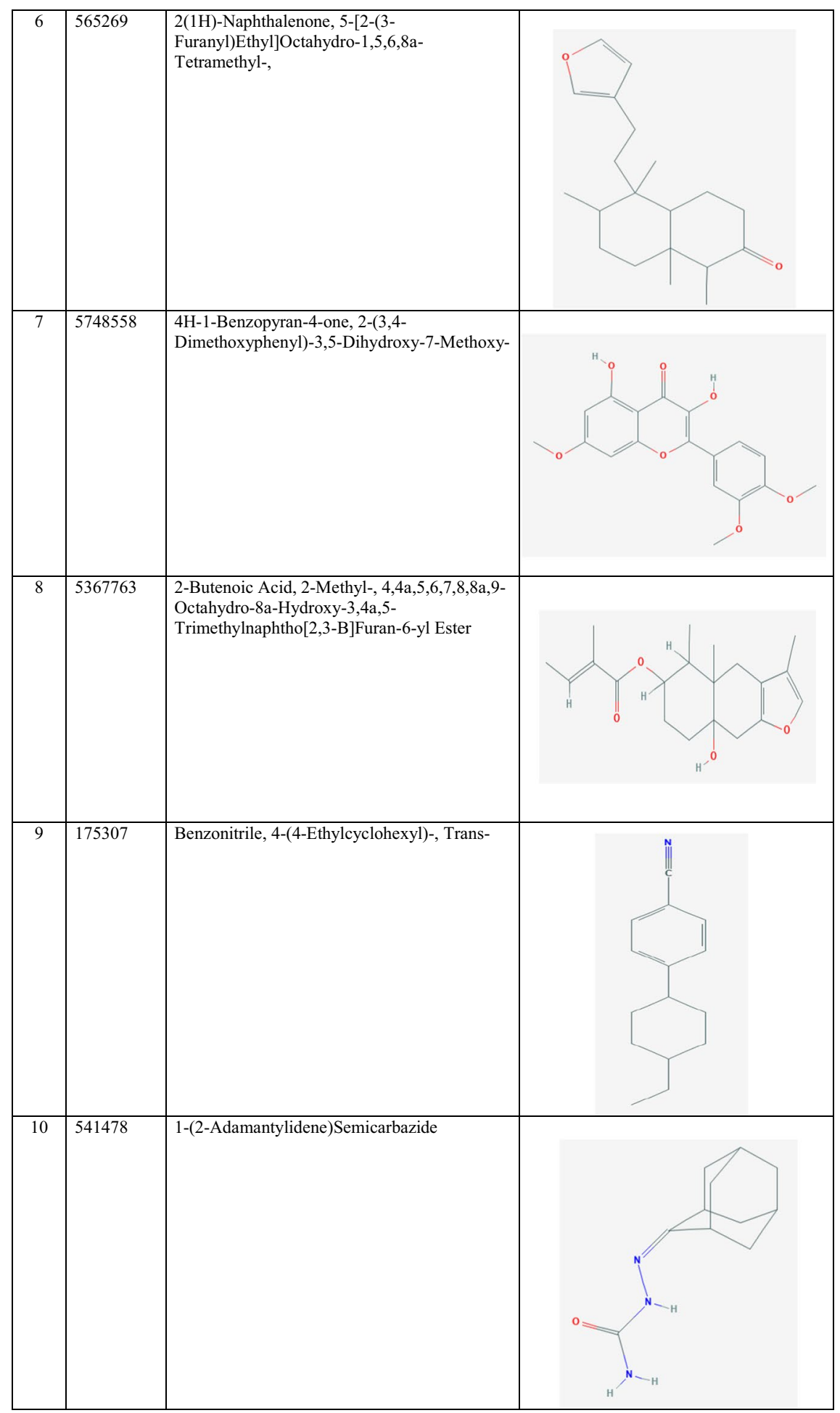


Publisher's Note Springer Nature remains neutral with regard to jurisdictional claims in published maps and institutional affiliations. 